\title{
Amelanotic melanoma masquerading as a pyogenic granuloma: caution warranted
}

\author{
Noah LW So *, CF Chan, Kenneth WY Ho, YL Lam \\ Hong Kong Med J 2014;20:265.e1-2 \\ DOI: 10.12809/hkmj133987
}

\section{Case}

In April 2012, a 69-year-old Chinese woman complained of a non-healing raised lesion over the lateral aspect of her left fifth toe which had developed 2 years earlier. It appeared to have started as a minor abrasion after wearing ill-fitting shoes. A painless swelling then developed over that site with occasional friction-induced bleeding. She attended several podiatry treatment sessions and tried applying topical medications such as silver nitrate. The lesion did not resolve, and increased in size and eventually developed into a pink nodule. Apart from hypercholesterolaemia, the patient was an otherwise healthy non-smoker and non-drinker who enjoyed sunbathing on the beach in her youth, often spending half a day under the sun.

On physical examination, a $1 \mathrm{~cm} \times 1 \mathrm{~cm}$ round and dull red nodule with superficial ulceration was noted on the lateral aspect of the left fifth toe. There were no signs of infection and no contact bleeding was evident (Fig). Given the history of minor

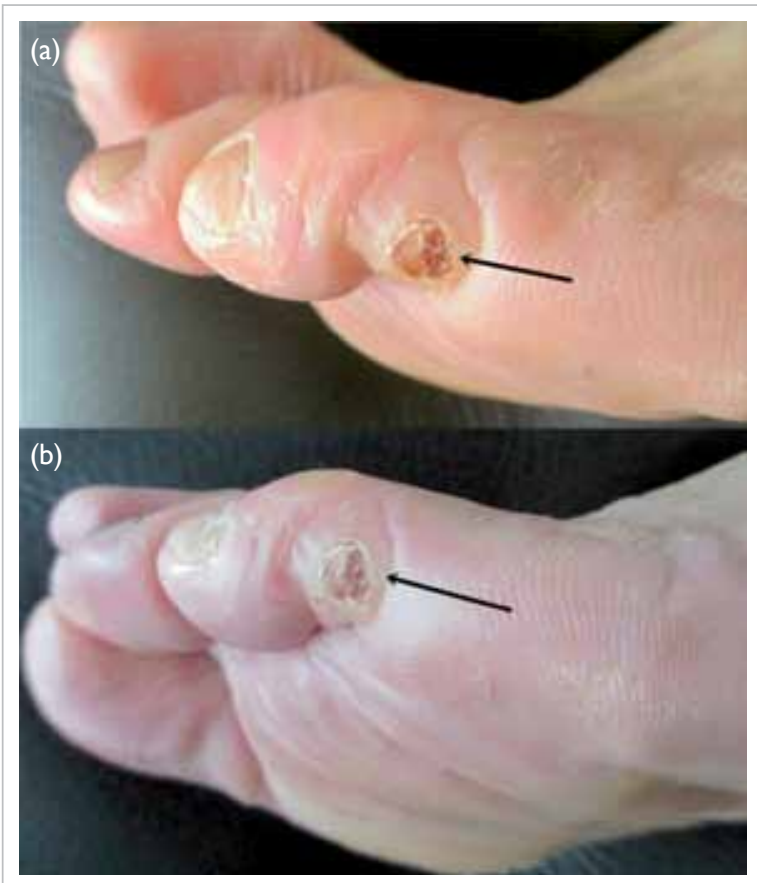

FIG. Left fifth toe before excision showing the malignant melanoma (arrow): (a) lateral view and (b) plantar view (oblique angle) trauma, tendency to bleed with minor friction and the appearance of the lesion, pyogenic granuloma was the main differential diagnosis. Owing to failure of repeated conservative treatment, excision of the lesion was performed.

Histology revealed it to be a malignant melanoma; no melanin pigment was detected but the tumour cells were positive for melanocytic markers. A staging positron emission tomography-computed tomography showed no metastasis. A wide resection involving ray amputation of the 4th and 5 th toes was performed to ensure a clear resection margin.

\section{Discussion}

Amelanotic melanoma is reported to account for about $1.8 \%$ to $8.1 \%$ of all melanomas. ${ }^{1}$ Cheung et $\mathrm{al}^{2}$ defined amelanotic melanoma as being unsuspected clinically and with melanin in less than $5 \%$ of the tumour cells. Because the diagnosis was not suspected clinically, he noted that excisional biopsies were seldom performed, and that if undertaken, transection of the melanoma was common. In their database of 1170 patients, McClain et $\mathrm{al}^{3}$ found that red melanomas accounted for $3.9 \%$ of all such malignancies and up to $70 \%$ of those that were amelanotic. Regarding prognosis, their review found no significant difference between red amelanotic melanomas and pigmented melanomas in terms of disease-free survival, overall survival, metastasis, and recurrence. In other words, the mortality of red amelanotic melanomas appeared comparable to that of pigmented melanoma.

In our patient, the most notable risk factor for developing melanoma was prolonged sunlight exposure but such a history may be missed if the diagnosis is not suspected. Amelanotic melanomas appear clinically indistinguishable from pyogenic granulomas. We therefore caution all our readers to the possibility of amelanotic melanoma presenting as seemingly benign red lesions. Whilst uncommon in China (age-standardised incidence of 0.2 per 100000 population and year), ${ }^{4}$ melanomas are highly malignant; both observation without investigation and excision without undertaking histology can delay the diagnosis with potentially disastrous consequences. The mnemonic 'ABCD' summarises features suggesting melanoma: Asymmetry, irregular Border, uneven Colour, Diameter of $>6 \mathrm{~mm}{ }^{4}$ The mnemonic RRR (Red, Raised lesion, Recent change ${ }^{3}$ ) 
is proposed additionally for the diagnosis of red References amelanotic melanomas. We recommend that for such red lesions of uncertain nature, referral to specialists experienced in managing melanomas is warranted.

NLW So *, MB, BS

CF Chan, MB, BS, FHKAM (Orthopaedic Surgery)

KWY Ho, MB, BS, FHKAM (Orthopaedic Surgery)

YL Lam, MB, ChB, FHKAM (Orthopaedic Surgery)

Department of Orthopaedics and Traumatology, Queen Mary Hospital, 102 Pokfulam Road, Hong Kong

* Corresponding author: noahlwso@gmail.com

1. Koch SE, Lange JR. Amelanotic melanoma: the great masquerader. J Am Acad Dermatol 2000;42:731-4.

2. Cheung WL, Patel RR, Leonard A, Firoz B, Meehan SA. Amelanotic melanoma: a detailed morphologic analysis with clinicopathologic correlation of 75 cases. J Cutan Pathol 2012;39;33-9.

3. McClain SE, Mayo KB, Shada AL, Smolkin ME, Patterson JW, Slingluff CL Jr. Amelanotic melanomas presenting as red skin lesions: a diagnostic challenge with potentially lethal consequences. Int J Dermatol 2012;51:420-6.

4. LeBoit PE, Burg G, Weedon D, Sarasin A, editors. Pathology and genetics of skin tumours (IARC WHO Classification of Tumours). Lyon: IARC Press; 2006. 